\title{
A case of airway occlusion in robotic surgery
}

\author{
Hasan Pathan · Sanjay Gulati
}

Received: 29 April 2007 / Accepted: 30 April 2007 / Published online: 6 June 2007

(C) Springer London 2007

\begin{abstract}
We present here a case of high airway pressure secondary to tracheal tube obstruction during roboticassisted laparoscopic radical prostatectomy, and the diagnostic dilemma.
\end{abstract}

Keywords Airway pressure $\cdot$ Robotic prostatectomy · Tracheal obstruction

\section{Introduction}

Robotic assisted radical prostatectomy is conducted using the Da Vinci surgical robot, controlled distantly from a console by the operating surgeon. There are five laparoscopic ports and the procedure requires a pneumoperitoneum for $3-4 \mathrm{~h}$ in an approximately $30^{\circ}$ Trendelenburg position.

\section{Case report}

A 48-year-old man, ASA I, presented for robotic radical prostatectomy. Induction was uneventful and the trachea was intubated with size 8.0 Portex tracheal tubing and fixed at the $22 \mathrm{~cm}$ mark at the angle of mouth. The lungs were mechanically ventilated without any problem. After securing the patient on the operating table, before surgical inci-

H. Pathan $(\bowtie)$

Department of Anaesthetics, Prince Philip Hospital,

Llanelli, SA14 8QF, UK

e-mail: hasanpathan@ doctors.org.uk

S. Gulati

Department of Anaesthetics, St Thomas' Hospital,

London, SE1 9RT, UK sion he was positioned in the Trendelenburg position to ensure good bilateral ventilation of the lungs without unduly high airway pressures.

On creation of the pneumoperitoneum there was a sudden increase in airway pressure up to $40 \mathrm{~cm}$ of water with a decrease in compliance of the lungs. Auscultation of the chest excluded endobronchial intubation or bronchospasm and tracheal suctioning showed the endotracheal tube was patent. There was high resistance to manual ventilation, which disappeared with abolition of the pneumoperitoneum. The endotracheal tube was withdrawn $1.5 \mathrm{~cm}$ and the pneumoperitoneum was created, again with reappearance of high airway pressure. There seemed to be a discrete cut off at $7 \mathrm{~cm} \mathrm{H}_{2} \mathrm{O}$, where the respiratory compromise occurred. This was independent of patient position. The clinical picture was suggestive of tension pneumothorax, and an on-table chest $\mathrm{X}$-ray was taken to investigate the pneumothorax, presumed secondary to a pleuro-peritoneal communication. The chest X-ray, however, showed no evidence of pneumothorax and the endotracheal tube was approximately $3 \mathrm{~cm}$ above the carinal angle.

At this we inserted a fibreoptic bronchoscope through the tracheal tube and observed that the bevel of the endotracheal tube was abutting against the tracheal wall. Because of the absence of a Murphy's eye in the tube, obstruction of the tube occurred on creation of the pneumoperitoneum. Changing the endotracheal tube for one with a Murphy's eye resolved the problem and the rest of the operation proceeded uneventfully.

\section{Discussion}

We concluded that the physical movement of the diaphragm and mediastinum upward on creation of the 
pneumoperitoneum caused obstruction of the endotracheal tube by the trachea itself. Alteration of the tracheal tube position with endobronchial intubation, leading to increase in airway pressure, has been reported during gynecological laparoscopy in the head down position $[1,2]$. We searched the literature and discovered reported cases of tracheal obstruction because of abutment against the tracheal wall $[3,4]$. We could not find any report of obstruction occurring with creation of a pneumoperitoneum only.

\section{References}

1. Joris JL (2000) Anesthesia for laparoscopic surgery. In: Miller RD (ed.) Anesthesia, 5th edn. Churchill Livingstone, Philadelphia 2003-2023

2. Chen PP, Chiu PT (1992) Endobronchial intubation during laparoscopic cholecystectomy (Letter). Anaesth Intensive Care 20:537-538

3. Stoen R, Smith-Erichsen N (1987) Airway obstruction associated with an endotracheal tube. Intensive Care Med 13(4):295-296

4. Brasch RC, Heldt GP, Hecht ST (1981) Endotracheal tube orifice abutting the tracheal wall: a cause of infant airway obstruction. Radiology 141(2):387-391 